\title{
Concerns about covert HIV testing are associated with delayed presentation in Ethiopian adults with suspected malaria: a cross-sectional study
}

Frew Tadesse ${ }^{1}$, Wakgari Deressa ${ }^{2 *}$ and Andrew W. Fogarty ${ }^{3}$

\begin{abstract}
Background: Although early diagnosis and prompt treatment is important in preventing mortality from malaria, presentation of symptomatic individuals is often relatively late. One possible contributing factor is that fear of covert human immunodeficiency virus (HIV) testing delays presentation in adults. We aimed to survey the magnitude of such concerns and their association with delayed presentation with suspected malaria.

Methods: The study design was a health facility-based cross-sectional survey. The study population consisted of adults with suspected malaria who presented to health centres in central Ethiopia. Data were collected on attitudes to HIV testing and the duration between onset of symptoms and treatment seeking for suspected malaria.

Results: Eight hundred and ten individuals provided data. Of these, 406 (50 \%) perceived that HIV testing was routinely done on blood donated for malaria diagnosis, and 327 (40\%) considered that community members delayed seeking medical advice because of these concerns. Concerns about HIV testing were associated with delays in attending for malaria diagnosis and treatment, with 117 individuals (29\%) of those with concerns about covert HIV testing waiting for 4 days or more, compared to 89 (22\%) of those who did not have any such concerns $(p=0.03)$. One hundred and twenty nine $(16 \%)$ individuals stated that concern about HIV testing was the main reason for the delay in seeking treatment, and $46 \%$ of these individuals presented after experiencing symptoms of malaria infection for three days or more compared to $22 \%$ of the 681 individuals who had no such concerns $(p<0.001)$. Analysis stratified by health centre demonstrated that these associations were a consequence of Meki health centre (odds ratio for duration of symptoms greater than 3 days if patient has concerns about HIV testing was 8.72; $95 \%$ confidence intervals 3.63 to 20.97).
\end{abstract}

Conclusions: In adults living in central Ethiopia, the perception that HIV testing accompanied the investigation of suspected malaria was common. This is likely to impede presentation for early medical treatment in some areas and represents a reversible risk factor that deserves further study.

Keywords: Malaria, HIV, Concern, Diagnosis, Delay, Stigma, Ethiopia

\footnotetext{
* Correspondence: deressaw@gmail.com

${ }^{2}$ Department of Preventive Medicine, School of Public Health, College of

Health Sciences, Addis Ababa University, Addis Ababa, Ethiopia

Full list of author information is available at the end of the article
} 


\section{Background}

Malaria is an important treatable cause of morbidity and mortality, with 3.4 billion people globally estimated to be at risk of infection in 2012, resulting in approximately 200 million cases of malarial infection and 600,000 deaths annually [1]. In Ethiopia, malaria is one of the most important public health problems, representing the commonest communicable disease [2] and imposing a high economic cost on the country [3]. As malaria is treatable with prompt medical care [4], the national malaria programme stresses the importance of early treatment-seeking behaviour for suspected infection [2].

Ethiopia is one of the countries in the sub-Saharan Africa that have a generalized human immunodeficiency virus (HIV) epidemic with about 750,000 people living with HIV/AIDS [5]. The prevalence of HIV infection among adults aged 15-49 years old in 2011 was estimated to be $4.2 \%$ in urban areas and $0.6 \%$ in rural areas [6]. Despite the availability of anti-retroviral treatment, individuals may be reluctant to undergo testing of their HIV status, as they do not wish to be exposed to the knowledge and social consequences of a potential positive diagnosis.

We recently reported data demonstrating that presentation of children with suspected malaria was delayed if their guardian were concerned that blood samples collected for malaria diagnosis were being covertly tested for HIV status without consent [7]. A similar hypothesis was tested in adults, speculating that concerns about covert HIV testing were common and resulted in delay in the presentation of symptomatic patients for investigation of malaria. This hypothesis was tested using a cross-sectional observational study design in Ethiopia in adults with suspected malaria visiting health centres.

\section{Methods \\ Study population}

The study design was a health facility-based crosssectional survey. This study was conducted in East Shewa Zone of Oromia Regional State in Ethiopia, where malaria is one of the leading health problems. Five health centres were included in the study and data were collected in October and November 2012, which represents the peak malaria transmission season in this part of Ethiopia. Each health centre is led by medically qualified clinicians, has diagnostic facilities for malaria and covers a population of approximately 20,000 individuals. All adults aged 16 years or over who presented with symptoms consistent with malaria and gave finger-prick blood for microscopic examination at the health centres were eligible to participate in the study. All participants gave informed consent and received standard treatment for their presenting condition.

\section{Sample size calculation}

The aim was to recruit 850 individuals. The total sample size allocated to each health centre was proportional to the total patients tested for malaria in the previous 3 months (June-August, 2012) and individuals were recruited consecutively until the estimated sample size was achieved. Assuming that $20 \%$ of patients had concerns about HIV testing in population and $50 \%$ have had symptoms for 5 days or less, it was estimated that the study would have over $90 \%$ power (5\% risk of type I error) to detect an absolute increase of $20 \%$ in patients who had concerns about HIV testing who experienced malaria symptoms for 5 days or more compared to those who had had no such concerns.

\section{Data collection}

A pre-tested structured questionnaire was initially developed in English and then back translated into local language (Afan Oromo) and used for data collection. The questionnaire collected data on socio-demographic characteristics, concerns about HIV testing and duration of symptoms. One data collector and one supervisor from each health centre were trained to recruit the study participants and implement the questionnaire. Subsequent diagnosis of malaria was done using blood film examination under microscopy.

\section{Statistical analysis}

The main exposure of interest was the response to the question 'Are you concerned about HIV testing when you visit a health facility for malaria diagnosis and treatment? All completed data were examined for completeness and consistency. Initial analysis used Mann-Whitney and Kruskal-Wallis tests to identify differences in the duration of symptoms between different measures of concerns about HIV testing and perceptions of these concerns in the wider community. As the differences observed were relatively small, with similar median values as a consequence of the structure of the data, the outcome variable of duration of time was categorized into either less than or equal to three days and more than three days. Statistical analysis used chi-squared testing and subsequent analysis by logistic regression stratified by health centre. The impact of urban and rural locations on the primary exposure was explored as the prevalence of HIV infection varied between these settings.

\section{Ethical considerations}

The study protocol was reviewed and approved by the Research and Ethics Committee of the School of Public Health at the College of Health Sciences. Informed consent was obtained from each participant and confidentiality was maintained. Lastly, information and education was given to the study subjects with regard to malaria 
prevention, control, and early diagnosis and adequate treatment, and about HIV counselling and testing.

\section{Role of the funding source}

The sponsors of the study had no role in study design, data collection, data analysis, data interpretation, or writing of the report. The corresponding author had full access to the data and had full responsibility for the decision to submit.

\section{Results}

\section{Study demographics}

A total of 810 adults provided data for analysis. The demographics of the study participants are reported in Table 1. Four hundred and fifty-seven individuals (56\%) reported having symptoms of suspected malaria lasting more than 2 days, and 75 (9\%) had sought health advice prior to the current presentation (Table 2). The overall prevalence of confirmed malaria was $25 \%$ for participants in the study.

\section{Concerns about HIV testing}

Four-hundred and six (50\%) individuals considered that HIV testing was applied to blood given for malaria testing at the health centre (Table 3); 233 (29\%) of individuals considered that many or almost all members of the community had similar beliefs that malaria testing also involved HIV testing; 327 (40 \%) of individuals considered that fear of HIV testing delayed presentation of individuals with suspected malaria. Participants who suspected that blood provided for malaria diagnosis was covertly tested for HIV had a median delay of three days (interquartile range IQR 2 to 4) from the start of their symptoms to clinical evaluation compared to a median of three days (IQR 2 to 3 ) for those who did not hold this belief $(p<0.01)$.

Concerns about HIV testing on blood donated for the diagnosis of malaria were associated with delays in attending for treatment, with 117 individuals $(57 \%)$ of those with concerns waiting for 4 days or more, compared to 89 (43\%) who did not have any such concerns $(p=0.03)$. One hundred and twenty nine (16\%) individuals stated that concern about HIV testing was the main reason for the delay in seeking treatment, and 59 (46\%) of these individuals presented after more than three days of symptoms compared to 147 (22\%) of individuals who did not consider fear of HIV testing the cause for their delay $(p<0.001)$. Table 4 demonstrates that delays in seeking treatment varied between the five health centres $(p<0.001$, chi-squared test). The stratified analysis suggested that much of the associations observed were driven by data from Meki health centre with an odds ratio for

Table 1 Characteristics of participants

\begin{tabular}{|c|c|c|c|c|}
\hline \multirow[t]{2}{*}{ Characteristics } & \multirow{2}{*}{$\begin{array}{l}\text { Total } \\
\text { (\%) } N=810\end{array}$} & \multicolumn{2}{|c|}{ Concern about covert HIV testing } & \multirow[b]{2}{*}{$p$ value $^{*}$} \\
\hline & & Yes (\%) $N=406$ & No (\%) $N=404$ & \\
\hline \multicolumn{5}{|l|}{ Location } \\
\hline Urban & $476(59)$ & $230(57)$ & $246(61)$ & \multirow[t]{2}{*}{0.22} \\
\hline Rural & $334(41)$ & $176(43)$ & $158(39)$ & \\
\hline \multicolumn{5}{|l|}{ Sex } \\
\hline Male & $397(49)$ & $189(47)$ & $208(51)$ & \multirow[t]{2}{*}{0.16} \\
\hline Female & $413(51)$ & $217(53)$ & $196(49)$ & \\
\hline \multicolumn{5}{|l|}{ Age (years) } \\
\hline $16-24$ & $313(39)$ & 159 (39) & $154(38)$ & \multirow[t]{4}{*}{0.09} \\
\hline $25-34$ & $299(37)$ & $155(38)$ & $144(36)$ & \\
\hline $35-44$ & $142(18)$ & $73(18)$ & $69(17)$ & \\
\hline $44+$ & $56(7)$ & $19(5)$ & $37(9)$ & \\
\hline \multicolumn{5}{|l|}{ Highest level of education } \\
\hline Illiterate & $209(26)$ & $119(29)$ & $90(22)$ & \multirow[t]{4}{*}{0.15} \\
\hline Literate but no formal education & $38(5)$ & $18(4)$ & $20(5)$ & \\
\hline Primary school & $276(34)$ & $133(33)$ & $143(35)$ & \\
\hline Secondary school or higher & $287(35)$ & $136(33)$ & $151(37)$ & \\
\hline \multicolumn{5}{|l|}{ Electricity in household } \\
\hline Yes & $529(65)$ & $255(63)$ & $274(68)$ & \multirow[t]{2}{*}{0.13} \\
\hline No & 281 (35) & 151 (37) & 130 (32) & \\
\hline
\end{tabular}

${ }^{*}$ Chi-squared test 
Table 2 History of suspected malarial symptoms

\begin{tabular}{|c|c|c|c|c|}
\hline \multirow[t]{2}{*}{ Factors } & \multirow[t]{2}{*}{ Total } & \multicolumn{2}{|l|}{ Location } & \multirow[t]{2}{*}{$p$ value* } \\
\hline & & Urban & Rural & \\
\hline \multicolumn{5}{|c|}{$\begin{array}{l}\text { Number of days of illness prior to } \\
\text { health centre attendance (\%) }\end{array}$} \\
\hline$<1$ & $78(10)$ & $53(11)$ & $25(7)$ & 0.02 \\
\hline 1 & $62(8)$ & $38(8)$ & $24(7)$ & \\
\hline 2 & $213(26)$ & $139(29)$ & $74(22)$ & \\
\hline 3 & $251(31)$ & $140(29)$ & 111 (33) & \\
\hline $4+$ & $206(25)$ & $106(22)$ & $100(30)$ & \\
\hline \multicolumn{5}{|c|}{$\begin{array}{l}\text { Sought health advice prior to } \\
\text { visiting current health centre (\%) }\end{array}$} \\
\hline Yes & $75(9)$ & $34(7)$ & $41(12)$ & 0.01 \\
\hline No & 735 (91) & $442(93)$ & $293(88)$ & \\
\hline \multicolumn{5}{|c|}{$\begin{array}{l}\text { Took antimalarial tablets prior to } \\
\text { attendance at health centre (\%) }\end{array}$} \\
\hline Yes & $65(8)$ & $23(5)$ & $42(13)$ & $>0.001$ \\
\hline No & $136(17)$ & $79(17)$ & $57(17)$ & \\
\hline No response & $609(75)$ & 374 (79) & $235(70)$ & \\
\hline \multicolumn{5}{|c|}{$\begin{array}{l}\text { Positive laboratory test for } \\
\text { malaria (\%) }\end{array}$} \\
\hline Yes & $204(25)$ & $108(23)$ & $96(29)$ & 0.05 \\
\hline No & $606(75)$ & 368 (77) & 238 (71) & \\
\hline
\end{tabular}

IQR interquartile range

${ }^{*}$ Chi-squared test

duration of symptoms greater than 3 days if patient had concerns about HIV testing of 8.72 (95\% confidence interval 3.63 to 20.97).

\section{Discussion}

This is the first quantitative study to specifically assess the prevalence of concerns about HIV testing and associations with the time to presentation at health centres of adults with suspected malaria living in Ethiopia. Our analysis shows that half of the individuals with suspected malaria were concerned that HIV testing was implemented on all blood sampled for the diagnosis of malaria, and that $40 \%$ of our respondents considered that these beliefs will result in relatively later presentation at medical facilities for symptomatic patients. Collectively, these concerns about covert HIV testing were associated with delayed presentation for management of suspected malaria, with these associations a consequence of data from Meki health centre in particular.

The study has a number of strengths including the prospective assessment of a priori hypothesis from a population of adults with suspected malaria, who were unaware of the hypothesis being tested, with a very high response rate (minimising bias). The main limitation of these data is the issue of generalisabilty to other cultural settings. Although these observations are valid within the communities in Central Ethiopia that we studied, it is impossible to assume that these concerns regarding HIV testing and delayed access to health care in general are applicable elsewhere. In addition, our study population could be biased by severity of disease, so that those with more advanced disease are unable to attend the health centres, and hence our observations are pertinent only to those who attend health centres with symptoms of malaria, although this is unlikely to account for the association between delayed presentation and concerns about HIV testing. Our data should thus be considered to be hypothesis generating, and further regional studies are required in a number of different settings to determine how prevalent the beliefs are that covert HIV testing accompanies malaria blood testing in high HIV prevalence countries.

A delay of over two days before obtaining medical assessment after the initiation of symptoms of suspected malaria occurred in $56 \%$ of our study population, and similar delays have been observed in Nigeria [8], Senegal [9], Ethiopia [10, 11] and India [12, 13]. However, our data were cross-sectional and demonstrating causality is not possible using this study design. Future studies should consider using representative prospective study designs to study local differences in baseline attitudes to HIV testing, and in particular their possible association with late presentation of patients with malarial symptoms, adjusting for potential confounding factors such as access to health facilities.

The current study was performed at the same time as a second study that tested a related hypothesis in children presenting with suspected malaria [7]. These data demonstrated that $51 \%$ of guardians of these children perceived that HIV testing was done on blood donated for malaria diagnosis, which is similar to the $50 \%$ reported in the current data. Children whose guardians were concerned about covert HIV testing in cases of suspected malaria presented later with a median delay of three days compared to those children whose guardians were not concerned about covert HIV testing who had a median value of two days. While antiretroviral testing and therapy is available in Ethiopia, the disease remains a public health concern with stigma of having HIV infection being a particular problem despite the regular promotion of health awareness campaigns to educate the local population. The analysis stratified by health centre demonstrated that the prevalence of concern about HIV testing was common across all the regions studied, with values ranging from 45 to $54 \%$ of the populations studied, suggesting that this was not localised to just one area. However, only in one health centre (Meki) did this translate into a delay in presentation, and further investigation is required to account for this. The fact that level of education attained does not modify the concerns 
Table 3 Impact of health beliefs of participants on duration of symptoms

\begin{tabular}{|c|c|c|c|c|c|}
\hline \multirow[t]{2}{*}{ Factors } & \multirow[t]{2}{*}{ Total (\%) } & \multirow{2}{*}{$\begin{array}{l}\text { Median duration of } \\
\text { symptoms, days }(\mathrm{IQR})^{*}\end{array}$} & \multicolumn{2}{|c|}{ Duration of symptoms } & \multirow[t]{2}{*}{$P$ value $^{*}$} \\
\hline & & & $\leq 3$ days & $\geq 4$ days & \\
\hline \multicolumn{6}{|c|}{$\begin{array}{l}\text { Concerned about HIV testing when you visit a health facility for } \\
\text { malaria diagnosis and treatment }\end{array}$} \\
\hline Yes & $406(50)$ & $3(2$ to 4$)$ & $289(48)$ & $117(57)$ & \multirow[t]{2}{*}{0.03} \\
\hline No & $404(50)$ & $\begin{array}{l}3(2 \text { to } 3) \\
p<0.01\end{array}$ & $315(52)$ & $89(43)$ & \\
\hline \multicolumn{6}{|c|}{ How sure that covert HIV testing is done on malaria samples } \\
\hline Do not believe & $404(50)$ & $3(2$ to 3$)$ & $316(52)$ & $88(43)$ & \multirow[t]{3}{*}{0.01} \\
\hline Maybe & $212(26)$ & 3 (2 to 3.5$)$ & $159(26)$ & $53(26)$ & \\
\hline Very/completely sure & $194(24)$ & $\begin{array}{l}3(2 \text { to } 4) \\
p=0.003\end{array}$ & $129(21)$ & $65(32)$ & \\
\hline \multicolumn{6}{|c|}{$\begin{array}{l}\text { Estimate of how many people in community believe that } \\
\text { malaria blood samples are also tested for HIV }\end{array}$} \\
\hline None & $269(33)$ & $2(1$ to 3$)$ & $219(36)$ & $50(24)$ & \multirow[t]{5}{*}{0.004} \\
\hline Few & $220(27)$ & 3 (2 to 3$)$ & $167(28)$ & $53(26)$ & \\
\hline Many & $188(23)$ & 3 (2 to 4$)$ & $126(21)$ & $62(30)$ & \\
\hline Almost all/All & $45(6)$ & 3 (2 to 4$)$ & $33(5)$ & $12(6)$ & \\
\hline Do not know & $88(11)$ & $\begin{array}{l}3(2 \text { to } 4) \\
p=0.001\end{array}$ & $59(10)$ & $29(14)$ & \\
\hline \multicolumn{6}{|c|}{$\begin{array}{l}\text { Consider that the fear of HIV testing is the reason for the delay } \\
\text { in people seeking an early diagnosis of malaria at health facility? }\end{array}$} \\
\hline Yes & $327(40)$ & 3 (2 to 4$)$ & $223(37)$ & $104(50)$ & \multirow[t]{3}{*}{$<0.001$} \\
\hline No & $334(41)$ & 2 (2 to 3 ) & $281(47)$ & $53(26)$ & \\
\hline Do not know & 149 (18) & $\begin{array}{l}3(2 \text { to } 4) \\
p=0.001\end{array}$ & $100(17)$ & $49(24)$ & \\
\hline \multicolumn{6}{|c|}{$\begin{array}{l}\text { Concerns about HIV testing are main reason for delay in } \\
\text { presenting this time }\end{array}$} \\
\hline Yes & $129(16)$ & 3 (2 to 3$)$ & $70(12)$ & $59(29)$ & \multirow[t]{2}{*}{$<0.001$} \\
\hline No & $681(84)$ & $\begin{array}{l}3(3 \text { to } 5) \\
p<0.001\end{array}$ & $534(88)$ & $147(71)$ & \\
\hline
\end{tabular}

IQR interquartile range

*Non parametric test as appropriate (Mann-Whitney test, Kruskall-Wallis test)

about covert HIV testing is an important negative finding, that should inform future investigations in this area, as these concerns are shared across all educational groups.

Our data can be compared with those from Gambella Region of Ethiopia in 2008, where the prevalence of refusal for HIV testing among women attending for antenatal care was $25 \%$ [14], suggesting that there may be a substantial minority of individuals in Ethiopia who do not want to take advantage of HIV testing to know their serological status. To date, sparse data exist on how attitudes to HIV impact on presentation with symptoms of malaria. Individuals living in rural Cote d'Ivoire who were offered a rapid diagnostic testing assay for malaria reported that $67 \%$ had concerns that the blood would be used for HIV

Table 4 Odds ratio of impact of health beliefs of participants on duration of symptoms stratified by health centre

\begin{tabular}{lllll}
\hline Health centre & $\begin{array}{l}\text { Total number } \\
\text { of individuals }\end{array}$ & $\begin{array}{l}\text { Number of individuals with } \\
\text { symptoms } \geq 4 \text { days (\%) }\end{array}$ & $\begin{array}{l}\text { Number of individuals concerned about } \\
\text { HIV testing when you visit a health facility } \\
\text { for malaria diagnosis and treatment (\%) }\end{array}$ & $\begin{array}{l}\text { Odds ratio of duration of symptoms } \\
\geq 4 \text { days if concerned about covert } \\
\text { HIV testing (95 \% confidence intervals) }\end{array}$ \\
\hline Abosto & 139 & $53(38)$ & $65(47)$ & $0.49(0.24$ to 0.98$)$ \\
Batu & 180 & $36(20)$ & $94(52)$ & $1.02(0.49$ to 2.14) \\
Bulbula & 147 & $17(12)$ & $79(54)$ & $1.26(0.45$ to 3.52$)$ \\
Meki & 175 & $48(27)$ & $92(53)$ & $8.72(3.63$ to 20.97) \\
Mojo & 169 & $52(31)$ & $76(45)$ & $1.67(0.87$ to 3.24$)$ \\
\hline
\end{tabular}


testing [15]. In Uganda, two separate qualitative studies explored the feasibility of introducing rapid diagnostic malaria assays. In the first qualitative study, the local population again expressed concern that blood samples collected for malaria could be used for HIV testing rather than malaria [16]. In the second qualitative study, again individuals were worried that in most communities people think that taking of blood means testing for HIV and some do not want their HIV status disclosed' [17].

\section{Implications for policy}

If concerns about HIV testing delay malaria diagnosis, then this is obviously a concern for the local authorities that provide public health services in these countries, as malaria is a common disease that infects approximately 200 million individuals annually [1] and it is well recognized that prompt treatment for those who present with the infection is important to reduce morbidity and mortality [18-20]. One option would be to evaluate further targeted education for the public [21, 22], so that awareness of the risk of delayed presentation with suspected malaria by the erroneous concern that covert HIV testing is administered to all blood tests is addressed directly. One other possible explanation for our data from this and our previous study in the same population [7] is that it is actually true, that at times healthcare workers test blood samples for HIV infection without fully informed consent of the patient. Future studies may wish to clarify this issue and that of the confidentiality of results in these communities, and could provide useful data to reassure the local population that their blood is only used for the purposes provided, which in itself may reduce some of the concerns observed in our study population.

\section{Conclusions}

These data suggest that concerns about covert HIV testing without informed consent are common in central Ethiopia, and that these may result in delayed presentation by adults with suspected malaria for medical treatment. This provides a relatively novel risk factor that inhibits prompt treatment of patients with malarial symptoms that is potentially reversible, and provides the option of testing non-medical interventions to improve earlier presentation and hence treatment for this common infection.

\section{Abbreviations}

HIV: human immunodeficiency virus; IQR: interquartile range.

\section{Competing interests}

The authors have declared that there are no competing interests.

\section{Authors' contributions}

FT was involved in proposal writing, designed the study and participated in coordination, supervision and the overall implementation of the project, analysed the data, drafted and finalized the manuscript. WD and AWF conceived the study and participated in all stages of the study and revision of the manuscript. AWF obtained funding for the study and checked the statistical analyses. All authors read and approved the final version of the manuscript.

\section{Acknowledgements}

Our thanks go to the Addis Ababa University School of Public Health for supporting the study. This study concept originated from a meeting with the Medical Officer at Zeway Health Centre in October 2011, who stated that it was his perception that concerns about covert HIV testing was the biggest obstacle to earlier presentation for testing for malaria in his district. We are grateful to the Oromia Regional Health Bureau, East Shewa Zone Health Department and respective District and Town Administration Health Offices for their support in facilitating the implementation of this study. Finally, we are very grateful for data collectors and study participants who willingly took part in this study. This study would not have been possible without their involvement. This work was supported by the University of Nottingham and Nottingham University Hospital Charity.

\section{Author details}

${ }^{1}$ School of Public Health, College of Health Sciences and Medicine, Jigjiga University, Jigjiga, Ethiopia. ${ }^{2}$ Department of Preventive Medicine, School of Public Health, College of Health Sciences, Addis Ababa University, Addis Ababa, Ethiopia. ${ }^{3}$ Division of Epidemiology and Public Health, University of Nottingham, Nottingham, UK.

Received: 28 September 2015 Accepted: 22 January 2016

Published online: 01 February 2016

\section{References}

1. WHO. World Malaria Report 2014. Geneva: World Health Organization; 2014.

2. Ministry of Health of Federal Democratic Republic of Ethiopia. National Malaria Guidelines. Addis Ababa: Federal Ministry of Health; 2012.

3. Deressa W, Hailemariam D, Ahmed A. Economic costs of epidemic malaria to households in rural Ethiopia. Trop Med Int Health. 2007;12:1148-56.

4. White NJ, Pukrittayakamee S, Hien TT, Faiz MA, Mokuolu OA, Dondorp AM. Malaria. Lancet. 2014;383:723-35.

5. Ministry of Health of Federal Democratic Republic of Ethiopia. Health and Health Related Indicators 2012/2013. Addis Ababa: Federal Ministry of Health; 2014.

6. Central Statistical Agency [Ethiopia] and ICF International. Ethiopia Demographic and Health Survey 2011. Addis Ababa, Ethiopia and Calverton, Maryland, USA; 2012.

7. Haji Y, Deressa W, Davey G, Fogarty A. Concerns about covert HIV testing are associated with delayed presentation of suspected malaria in Ethiopian children: a cross-sectional study. Malar J. 2014;13:310.

8. Agu A, Nwojiji J. Childhood malaria: mothers' perception and treatmentseeking behaviour in a community in Ebonyi State, South East Nigeria. J Community Med Prim Health Care. 2005;17:45-50.

9. Smith LA, Bruce J, Gueye L, Helou A, Diallo R, Gueye B, et al. From fever to anti-malarial: the treatment-seeking process from rural Senegal. Malar J. 2010;9:333.

10. Paulander J, Olsson H, MLemma H, A. G, Sebastian S. Knowledge, attitudes and practice about malaria in rural Tigray, Ethiopia. Global Health Action. 2009; doi:10.3402/gha.v3402i3400.1839.

11. Deressa W, Chibsa S, Olana D. Treatment seeking of malaria patients in East Shewa Zone of Oromia, Ethiopia. Ethiop J Health Dev. 2003;17:9-15.

12. Matta S, Khotar A, Sachdev T. Assessment of knowledge about malaria among patients reported with fever: a hospital-based study. J Vector Borne Dis. 2004;41:27-31.

13. Das A, Ravindran T. Factors affecting treatment-seeking for febrile illness in a malaria endemic block in Boudh district, Orissa, India: policy implications for malaria control. Malaria Journal. 2010;9:377.

14. Fanta W, Worku A. Determinants for refusal of HIV testing among women attending for antenatal care in Gambella Region, Ethiopia. Reprod Health. 2012;9:8.

15. Comoe CC, Outattara AF, Raso G, Tanner M, Utzinger J, Koudou BC. Willingness to use a rapid diagnostic test for malaria in a rural area of central Cote d'Ivoire. BMC Public Health. 2012;12:1089.

16. Mukanga D, Tibenderana JK, Kiguli J, Pariyo GW, Waiswa P, Bajunirwe F, et al. Community acceptibility of use of rapid diagnostic tests for malaria by community health workers in Uganda. Malar J. 2010;9:203. 
17. Mbonye AK, Ndyomugyenyi R, Turinde A, Magnussen P, Clarke S, Chandler C. The feasibility of introducing rapid diagnostic tests for malaria in drug shops in Uganda. Malar J. 2010;9:367.

18. McGready R, Boel M, Rijken MJ, Ashley EA, Cho T, Moo O, et al. Effect of early detection and treatment on malaria related maternal mortality on the North-Western border of Thailand, 1986-2010. PLoS ONE. 2012;7:e40244.

19. Durrheim D, Frieremans S, Kruger P, Mabuza A, de Bruyn J. Confidental enquiry into malaria deaths. Bull World Health Organ. 1999;77:263-6.

20. Ejov M, Tun T, Aung S, Lwin S, Sein K. Hospital-based study of severe malaria and associated deaths in Myanmar. Bull World Health Organ. 1999:77:310-4.

21. Rhee M, Sissoko M, Perry S, Mcfarland W, Parsonnet J, Doumbo O. Use of insecticide-treated nets (TTNs) following a malaria edadication intervention in Piron, Mali: a control trial with systematic allocation of households. Malar J. 2005:4:35.

22. Ayi I, Nonaka D, Adjovu JK, Hanafusa S, Jimba M, Bosompem KM, et al. School-based participatory health education for malaria control in Ghana: engaging children as health messengers. Malar J. 2010;9:98.

Submit your next manuscript to BioMed Central and we will help you at every step:

- We accept pre-submission inquiries

- Our selector tool helps you to find the most relevant journal

- We provide round the clock customer support

- Convenient online submission

- Thorough peer review

- Inclusion in PubMed and all major indexing services

- Maximum visibility for your research

Submit your manuscript at www.biomedcentral.com/submit
Biomed Central 